\title{
Adult Stem Cell Therapy in Liver Cirrhosis Management: Current Practices and Future Perspectives
}

\author{
Sellamuthu Subbanna Gounder ${ }^{1}$, Radha Kodiappan ${ }^{2}$, Soon Choy Chan ${ }^{3}$, Abhi Veerakumarasivam $^{4}$ \\ and Baskar Subramani ${ }^{1 *}$
}

\author{
${ }^{1}$ Nichi-Asia Life Science Sdn Bhd, Selangor, Malaysia \\ ${ }^{2}$ Perdana University Royal College of Surgeon Ireland, Perdana University, 43400 Serdang, Selangor Darul Ehsan, Malaysia \\ ${ }^{3}$ Perdana University School of Foundation Studies (PUSFS), Perdana University, 43400 Serdang, Selangor Darul Ehsan, \\ Malaysia
}

${ }^{4}$ Sunway Institute for Healthcare Development, Sunway University, Bandar Sunway, 47500 Subang Jaya, Selangor Darul Ehsan, Malaysia

*Corresponding author: Dr. Baskar Subramani, Nichi-Asia Life Science Sdn Bhd, (786331-D) 57, Block F, Jalan Teknology 3/9 Bistari "De" Kota, Kota Damansara PJU 5, 47810 Petaling Jaya Selangor Darul Eshan, Malaysia, Tel: +603-61421920/21, Fax: +603-6142, E-mail: baskar@niscell.com

\begin{abstract}
Liver cirrhosis is a leading cause of mortality worldwide. Although treatable by liver transplantation, quality of life is unlikely to drop in all the patients after five years. The shortage of matching donors and the high risk of surgical-associated complications further limits the therapeutic potential of transplantation. Since adult stem cells can be effectively differentiated into hepatocyte-like cells, the potential to translate this utility as a therapeutic alternative has been considerably explored. The bone marrow serves as an ideal source of Hematopoietic Stem Cells (HSCs) and Mesenchymal Stem Cells (MSCs). Although both of these cells have in vivo ability to generate hepatocytes-like cells, MSCs are more potent. Autologous and allogeneic adult stem cell-based therapies have shown promising results in restoring liver function in cirrhosis patients. However, there is still a lack of consensus with regards to the optimum standardization of stem cell source, type, dosage, and mode of transplantation. Many variations exist across the different clinical studies conducted and this hampers the mainstream clinical realization of adult stem cell-based therapy for liver cirrhosis. Thus, this article attempts to review and consolidate the various cellular source, type, dose, and mode of delivery permutations across the various clinical studies published to date.
\end{abstract}

\section{Introduction}

Liver cirrhosis is an end-stage pathological condition that results from a range of chronic liver diseas- es. Many chemicals, viruses and toxic substances have been associated with the development of cirrhosis. It is usually characterized by hepatocyte necrosis, defenestration, collagen deposition contributes to fibrosis that ultimately lead to the cumulative loss of liver function $[1,2]$. In addition, liver cirrhosis is also characterized by the formation of regenerative nodules that eventually replace the entire liver architecture, leading to decreased blood flow throughout the liver [1]. Besides reduced quality of life, individuals with liver cirrhosis also have an increased risk of liver cancer. As a result, liver cirrhosis accounts for more than one million worldwide deaths annually and an even greater disease-associated morbidity burden [3]. The treatment of cirrhosis is designed to hinder further liver damage, treat cirrhotic complications and prevent liver cancer. Unfortunately various therapeutic-associated limitations have led to the increase in fatality rates over the years [4]. At present the only effective therapeutic option is Orthotopic Liver Transplantation (OLT). OLT for liver cirrhosis result in a 5 -year survival rate of about $70 \%$. However, the efficacy and widespread application of OLT is hampered by the shortage of matching donors, surgery-associated morbidities and risk of graft-rejection $[5,6]$. These limitations have driven researchers and clinicians to devel-

Citation: Gounder SS, Kodiappan R, Chan SC, Veerakumarasivam A, Subramani B (2017) Adult Stem Cell Therapy in Liver Cirrhosis Management: Current Practices and Future Perspectives. Int J Stem Cell Res Ther 3:049. doi.org/10.23937/2469-570X/1410049

Received: August 18, 2017: Accepted: September 23, 2017: Published: September 26, 2017

Copyright: (C) 2017 Gounder SS, et al. This is an open-access article distributed under the terms of the Creative Commons Attribution License, which permits unrestricted use, distribution, and reproduction in any medium, provided the original author and source are credited. 
op novel therapeutic strategies to reduce the morbidity and mortality burden of the disease.

Stem cell therapy has emerged as an attractive therapeutic approach for a myriad of life-threatening diseases in recent years. Specifically, cell-based therapies for liver cirrhosis have successfully progressed from preliminary laboratory and pre-clinical evaluations. Several studies have demonstrated that residential and non-residential liver stem cells have the ability to differentiate into hepatocyte-like cells or bile duct epithelial cells, and more pertinently restore liver function [7-11]. The mechanistic action of stem cell-mediated restoration of liver function in liver cirrhosis has not been fully defined. However, several mechanisms have been proposed. Some studies suggest the presence of autocrine signalling, whereby the transition of stem cells into hepatocytes-like cells is induced by the secretion of Hepatocyte Growth Factor (HGF) [12,13]. In contrast, some studies postulate that paracrine signaling mediates liver regeneration through revascularization and enhancing repopulation of endogenous cells in necrotic tissue through the secretion of various cytokines and growth factors $[6,14]$. Stem cells may also attenuate liver fibrogenesis by inhibiting the activation of hepatic stellate cells (cells responsible for the secretion of extracellular matrix components that include collagen and adhesive glycoproteins) via stem cell-derived cytokines and growth factors such as IL6, IL10, TNF $\alpha$ and HGF. For example, HGF directly suppresses hepatic stellate cell activation by blocking the Extracellular Signal-Regulated Kinase (ERK) and Transforming Growth Factor (TGF- $\beta$ ) signaling pathways [15-17].

Various sources and types of stem cells have been identified as potential cell-based therapeutics for the management of liver failure or cirrhosis (Figure 1). Embryonic stem cells and induced-pluripotent stem cells have been shown to be most potent in the context of their ability to differentiate into hepatocyte-like cells in both, animals and humans. However, genomic instability, oncogenic risk and ethical issues continue to limit their widespread clinical translation $[18,19]$. In contrast, the application of multipotent adult stem cells has been identified as being safe with no significant ethical constraints. Various obstacles such as limited knowledge in stem cell biology, insufficient cell number and technological challenges surrounding in vitro expansion that previously hampered the utility of these cells have been supplanted in recent years. As a result, a number of studies involving adult stem cell-based therapy of liver cirrhosis patients have shown promising results without significant clinical impediments [20].

Adult stem cells, which include Hematopoietic Stem Cells (HSCs), Programmed Progenitor Cells (PPS) and stromal or Mesenchymal Stem Cells (MSCs) are primarily generated from the bone marrow. Adult stem cells have also been identified in specific niches in many organs and tissues. These stem cells have the ability to differentiate into many types of cells and tissues, including neurons, cardiac myocytes, hepatocytes and pancreatic cells by Preston, et al. 2003. Numerous clinical studies have demonstrated that the use of bone marrow-derived stem cells is not only safe but also results in significant improvement in minimizing disease progression. Therefore, autologous bone marrow-derived stem cells have been used to treat end-stage liver failure or cirrhosis [20-22]. Due to their unique self-renewal and multi-differentiation potential, HSCs were thought to have the most regenerative potential. This was supported by findings that bone marrow-derived CD34+ HSCs have the ability to restore liver function within a short term follow-up [21]. However, several recent pre-clinical and clinical studies have demonstrated that MSCs from bone marrow have greater regenerative effects than HSCs. These cells have endodermal lineage differ-

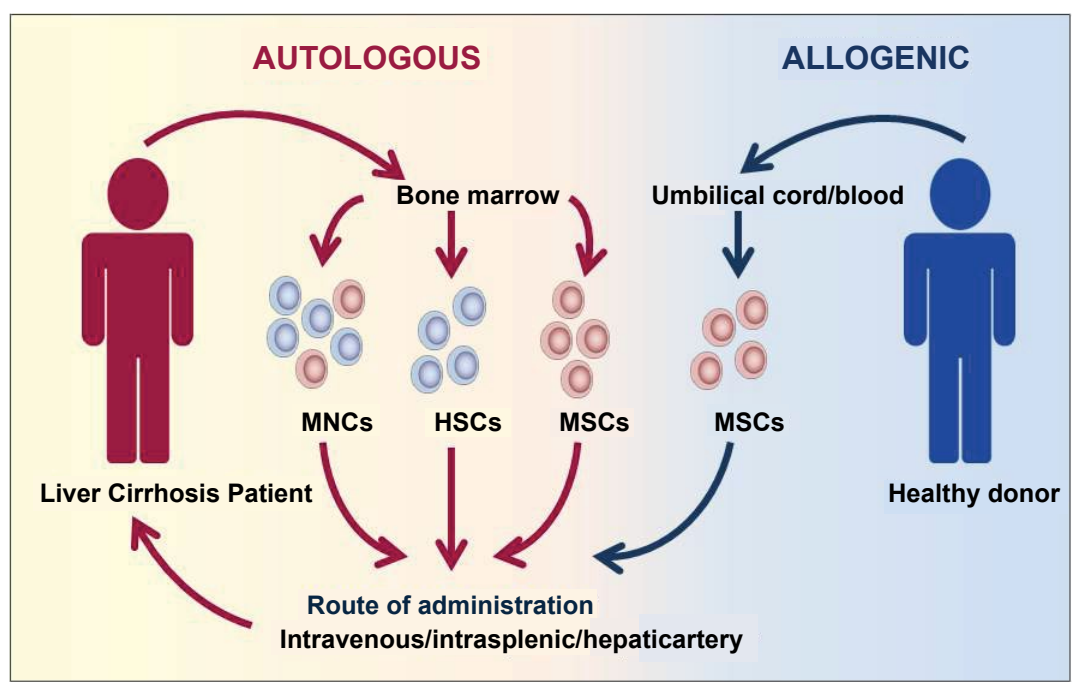

Figure 1: Autologous and allogenic adult stem cell-based therapy for liver cirrhosis. Multipotent adult stem cells, including HSCs and MSCs (collectively known as MNCs) are potent therapeutic agents in the management of liver cirrhosis. Autologous transplantation involves the transfer of adult stem cells derived from the patient's own bone marrow back into the patient via intravenous, intrasplenic or the hepatic artery. While, a similar route of administration is applied in allogenic therapy, the MSCs are obtained from umbilical cord or blood of a healthy donor. 
Table 1: Therapeutic applications of bone marrow derived-stem cells in liver cirrhosis patients.

\begin{tabular}{|c|c|c|c|c|c|}
\hline Cell type & Dose & Route & Sample size (n) & Outcome & Reference \\
\hline $\mathrm{BM}$ & Single median dose $/ 1 \times 10^{8}$ & Hepatic artery & 10 & $\begin{array}{l}\text { Increased serum albumin; } \\
\text { Decreased bilirubin }\end{array}$ & [22] \\
\hline BM & $\begin{array}{l}\text { Single median dose/240-1027 } \\
\times 10^{6}\end{array}$ & Intravenous & 22 & $\begin{array}{l}\text { Increased serum albumin; } \\
\text { Decreased bilirubin and ascites }\end{array}$ & [34] \\
\hline BM & Single median dose $/ 5.2 \times 10^{9}$ & Peripheral vein & 9 & $\begin{array}{l}\text { Increased serum albumin; } \\
\text { Decreased CPS }\end{array}$ & [20] \\
\hline BM & $\begin{array}{l}\text { Single median dose } / 0.48-1.48 \\
\times 10^{8} / \mathrm{kg} \text { body weight }\end{array}$ & Peripheral vein & 10 & $\begin{array}{l}\text { Increased serum albumin; } \\
\text { Decreased ascites }\end{array}$ & {$[11]$} \\
\hline BM & Single median dose $/ 8 \times 10^{9}$ & Peripheral vein & 5 & $\begin{array}{l}\text { Increased serum albumin and } \\
\text { protein; Decreased prothrombin } \\
\text { time }\end{array}$ & [35] \\
\hline BM & $\begin{array}{l}\text { Single median unspecified } \\
\text { dose }\end{array}$ & Hepatic artery & 30 & $\begin{array}{l}\text { Increased serum albumin; } \\
\text { Decreased CPS }\end{array}$ & [72] \\
\hline
\end{tabular}

entiation potential and thus can differentiate into hepatocyte-like cells. These findings have shifted the liver cirrhosis therapeutic research focus to the transplantation of bone marrow-derived MSCs [13,23]. Nevertheless, recent evidence suggest that co-transplantation of an enriched multipopulation of stem cells, instead of any specific adult stem cells, has a greater impact on therapeutic outcome on end stage liver disease [24].

Apart from the use of autologous stem cells derived from the bone marrow, allogeneic stem cells, specifically MSCs, have been identified as a potential therapeutic tool in treating liver cirrhosis. Most of these allogeneic stem cells are isolated from the umbilical cord blood, Wharton's jelly, amniotic fluid, dental pulp and adipose tissues. Despite their hypoimmunogenic and regenerative properties, not many clinical studies have been conducted to demonstrate the clinical utility of allogeneic MSC in treating liver cirrhosis patients [25]. However, a recent clinical study suggests that umbilical cord-derived MSC transplantation has the potential to improve liver function without any noticeable side-effects in patients [26].

Despite the growing evidence pertaining to the enormous therapeutic potential of stem cells in liver cirrhosis management, the seamless clinical translation from bench to bedside is still impeded by multiple factors. Many variations across different studies hamper the determination of optimum standards for stem cell source, type, dosage, and mode of transplantation. The lack of a generalized consensus will continue to result in divergent experimental protocols in current and future clinical studies. These variations affect the ability of the researchers to make direct and objective comparisons that unfortunately further inhibits the mainstream clinical realization of adult stem cell-based therapy for liver cirrhosis. Thus in this article, we attempt to review and highlight the various cellular source, type, dose, and mode of delivery permutations across the clinical studies published to date.

\section{Bone Marrow-Derived Mononuclear Cells (BM- MNCs) in Autologous Liver Cirrhosis Therapy}

Numerous studies have revealed that bone marrow-derived stem cells (HSCs and MSCs) are safer and have great therapeutic potential to treat diseases such as parkinson, myocardial infarction, acute renal failure, knee and spinal cord injuries $[27,28]$. The percentage of HSCs and MSCs in human bone marrow is approximately 1 in $1 \times 10^{4}$ cells and 1 in $5 \times 10^{4}$ cells, respectively. Thus the MSC population is about 5-fold smaller than that of HSCs [29]. These stem cells, collectively known as Mononuclear Cells (MNCs) have the potential to differentiate into hepatocyte-like cells in both, in vitro and in vivo conditions [20].

Several clinical trials have suggested that the transfusion of autologous BM-MNCs effectively promote liver regeneration by reducing fibrosis, improve liver function and survival rates $[30,31]$ (Table 1 ). These extracellular matrix remodeling Matrix Metalloproteinases (MMPs) exert their anti-fibrotic effects by inducing apoptosis in hepatic stellate cells [32,33] the cells primarily responsible for the initiation and progression of hepatic fibrosis [2]. The therapeutic utility of BM-MNC has been largely evaluated in liver cirrhosis patients associated with hepatitis $B$, hepatitis $C$, alcoholic liver diseases, and decompensated and biliary duct liver cirrhosis. ChildPugh Score (CPS) and Model for End-Stage Liver Disease (MELD) are the two important scoring systems widely used to evaluate the prognosis of patients with liver diseases $[9,10]$, including cirrhosis. The CPS considers five clinical factors, three of which assess the synthetic function of the liver (i.e., total bilirubin level, serum albumin level and international normalized ratio, or INR) and 2 of which are based on clinical assessments (i.e., degree of ascites and hepatic encephalopathy). The MELD is a newer scoring system that has been developed to determine priority for liver transplantation. Disease progression is calculated based on the MELD score. For example, if the MELD score decreases from the baseline before therapy, the therapy is deemed to be successful. These 
factors or parameters are generally used to determine liver function qualitatively and quantitatively.

A study in 2007 showed that the administration of an average of $100 \times 10^{6} \mathrm{BM}-\mathrm{MNCs}$ through the hepatic artery in patients $(n=10)$ with liver cirrhosis was practically safe and able to stimulate an increase in albumin levels and decrease of bilirubin levels; suggesting an improvement in liver function [22]. In addition, patients who received transfusions with the highest amounts of BM-MNCs had the most significant improvement in liver function as compared to those who received transfusions of lower amounts of BM-MNCs. Similarly, we also demonstrated the efficacy of intravenous administration of 240 to $1028 \times 10^{6}$ BM-MNCs in chronic liver disease patients $(n=22)$ [34]. Patients in this study showed good clinical outcome. The serum albumin levels increased while the bilirubin levels and ascites decreased. In another study involving nine liver cirrhosis patients treated with a single median dose of $5.2 \pm 0.63 \times 10^{9}$ BM-MNCs via the peripheral vein, it was found that the patients showed improved serum albumin levels and CPS within a short follow-up period of 24 weeks [20]. A recent study revealed that a single dose of $0.48-1.48$ $\times 10^{8} / \mathrm{kg}$ body weight of BM-MNCs via the peripheral vein showed significant improvement in the outcome of 10 patients with hepatitis B-associated liver cirrhosis without causing any serious side-effects [12]. Besides increasing serum albumin levels and diminishing ascites, the MRI scans of these patients showed that their liver volume increased by $80 \%$. The follow-up study involving alcoholic liver cirrhosis patients $(n=5)$ infused with a single median peripheral vein injection of $8.0 \pm 7.3 \times 10^{9}$ BM-MNCs showed remarkable improvement in serum albumin, protein and prothrombin levels [35].

Although, these BM-MNC clinical studies have shown promising liver function improvement effects, the magnitude of efficacy and overall Quality of Life Index (QULI) varied significantly between studies. The inconsistencies observed in the measured clinical end points are associated with the differences in treatment protocols, including the dose and duration of treatment. For instance, a recent clinical trial of BM-MNC transplantation in patients with decompensated alcoholic liver disease failed to expand the population of hepatic progenitor cells or improve liver function [36]. However, these could be due to the number of BM-MNC $(0.47 \pm 0.15$ $\left.\times 10^{8}\right)$ used in this study which is lower than any other studies $[22,36]$. It has been estimated that at least $28 \times 10^{10}$ healthy hepatocytes or about $1-5 \%$ of the total liver mass are essential for normal liver function [37-39]. Due to the lack of understanding of the exact mechanism by which BM-MNC induces liver regeneration, it is very hard to predict the number of BM-MNCs that are required to restore physiological liver function. Many clinical trials have proposed that by increasing the number of BM-MNCs within a safe therapeutic window, patient prognosis improves. Thus, one dose of $2 \times 10^{8}$ BM-MNC per kg body weight could be considered as an optimum dose for future studies. Based on existing evidence, there are no significant variations between the routes of administration [40].

\section{Bone Marrow-Derived Hematopoietic Stem Cells (BM-HSCs) in Autologous Liver Cirrhosis Therapy}

Growing evidence suggest that bone marrow-derived HSCs have the plasticity to differentiate into non-hematopoietic lineage cells, such as endothelial cells, fibroblasts, myocytes, nephrons and hepatocytes [30,40,41]. In fact, these bone marrow-derived stem cells are known to play a primary role in liver regeneration. The increased mobilization of bone marrow-derived stem cells to the liver has been shown to exert beneficial effects in rodent cirrhosis model systems [42-44]. The paradigm of stem cell-based therapy has now shifted towards the enrichment of specific bone marrow-derived stem cells, particularly CD34+, CD45+ and CD133+ HSCs obtained from the peripheral blood [20,45]. The enrichment of peripheral BM-HSCs can be achieved by either purification of aspirated BM or the mobilization of HSCs using Granulocyte Colony Stimulating Factor (G-CSF). However, the administration of G-CSF has been fraught by several complications, such as a high risk of tumor progression and spontaneous rupture of the spleen $[46,47]$. The direct aspiration of bone marrow and the enrichment of hematopoietic cell populations in the peripheral blood by either sorting or ex vivo expansion of HSCs has been shown to be a safer therapeutic approach.

The transplantation of BM-HSCs at a dose range of between $1 \times 10^{6}$ to $2 \times 10^{8}$ cells in liver cirrhosis patients either through the portal vein, peripheral vein, or he-

Table 2: Therapeutic applications of bone marrow-derived HSCs in liver cirrhosis patients.

\begin{tabular}{|c|c|c|c|c|c|}
\hline Cell type & Dose & Route & Sample size (n) & Outcome & Reference \\
\hline BM-HSC & $\begin{array}{l}\text { Single median } \\
\text { dose } / 5 \times 10^{9}\end{array}$ & Peripheral vein & 10 & $\begin{array}{l}\text { Increased serum albumin; } \\
\text { Decreased CPS }\end{array}$ & [20] \\
\hline BM-HSC & $\begin{array}{l}\text { Single median } \\
\text { dose } / 2 \times 10^{8}\end{array}$ & $\begin{array}{l}\text { Portal vein }(n=3) \text {; Hepatic } \\
\text { artery }(n=2)\end{array}$ & 5 & $\begin{array}{l}\text { Increased serum albumin; } \\
\text { Decreased bilirubin and ascites }\end{array}$ & {$[50]$} \\
\hline BM-HSC & $\begin{array}{l}\text { Single median } \\
\text { dose } / 2.3 \times 10^{8}\end{array}$ & Hepatic artery & 9 & $\begin{array}{l}\text { Increased ALT, AST; Decreased } \\
\text { CPS, serum bilirubin and ascites }\end{array}$ & [51] \\
\hline BM-HSC & $\begin{array}{l}\text { Single median } \\
\text { dose/range } \\
\text { between } 1 \times 10^{6} \text { - } \\
2 \times 10^{8}\end{array}$ & Portal vein/hepatic artery & 5 & $\begin{array}{l}\text { Increased serum albumin; } \\
\text { Decreased serum bilirubin }\end{array}$ & [52] \\
\hline
\end{tabular}


patic artery has been considered safe and tolerable $[48,49]$. Following these safety profile reports, a number of clinical studies have demonstrated the possible beneficial effects of bone marrow-derived HSCs in patients with liver cirrhosis (Table 2). A pilot study involving 10 patients with hepatitis B- or C-associated liver cirrhosis showed that a single median dose of about $5 \times 10^{9} \mathrm{BM}$ HSCs via the peripheral vein significantly improved albumin levels and CPS [20]. In a parallel study, chronic liver failure patients who underwent portal vein $(n=3)$ and hepatic artery $(n=2)$ infusion of a single median dose of $2 \times 10^{8}$ autologous BM-HSC showed an improvement without any complications or side effects [50]. These patients' serum albumin levels increased while the serum bilirubin levels decreased. On the contrary, in four patients with decompensated cirrhosis, a single dose of $3-10 \times 10^{6}$ of BM-HSC infused via the hepatic artery resulted in severe adverse effects including nephropathy and hepatorenal syndrome [49]. Due to the failure of the treatment, the study was terminated prematurely.

In another study, the infusion of BM-HSCs at a dose of $2.3 \times 10^{8}$ cells via hepatic artery in nine patients showed desirable outcomes without any adverse effects [51]. These patients showed significant improvement in serum Alanine Transaminase (ALT), and Aspartate Transaminase (AST) levels one week post-infusion. Twelve weeks after infusion, the serum bilirubin and CPS levels were significantly reduced and ascites improved in 7 out of 9 patients. In another clinical study, the feasibility and the efficacy of CD34+ HSC infusion in five chronic liver disease patients was assessed [52]. In this study, patients were injected with a single dose of HSCs ranging between $1 \times 10^{6}$ to $2 \times 10^{8}$ cells via either the portal vein or hepatic artery. The Quality of Life Index (QULI) was found to be considerably improved up to 6 months post-infusion. Patient serum bilirubin levels only began to increase 18 months after the infusion. This clinical study provides evidence that infusion of CD34+ HSCs is relatively safe without any complications or side effects in the long term. Despite the diverse range of BM-HSCs $\left(1 \times 10^{6}\right.$ to $2.3 \times 10^{8}$ cells) per infusion, almost all the clinical studies have shown that these stem cells have the ability to restore liver function. However, the long term therapeutic effect in mitigating disease progression is rather limited. Thus, BM-HSC-based therapy could be considered as a first-line therapy before OLT or longterm multiple infusion therapy.

\section{Bone Marrow-Derived Mesenchymal Stem Cells (BM-MSCs) in Autologous Liver Cirrhosis Therapy}

Mesenchymal stem cells possess unique biological properties. They are not only able to differentiate into a broad range of mesodermal lineages but also other embryonic lineages. These cells amplify their clinical utility through other innate properties such as their self-renewing capacity, homing and migration ability, immunosuppressive potential, and paracrine effects such as anti-inflammation, anti-apoptosis, anti-fibrosis/anti-scarring (matrix remodeling) and angiogenesis [28,53]. These features make MSCs the most potent and preferred therapeutic tool in regenerative medicine. Several experimental and pre-clinical studies demonstrate that MSCs seem to have a crucial role in the improvement of liver regeneration in many liver disease models, especially in cirrhosis. Most clinical studies utilizing MSCs to treat liver cirrhosis are in phase I or II trials. Much of the focus is to evaluate the safety, feasibility and efficacy of the treatment (Table 3). While a number of clinical trials have used various sources of MSCs for liver cirrhosis treatment, BM-MSC-based therapy has successfully entered into phase III trials. Since phase III clinical trials involve a large number of patients, they provide more robust evidence of the potency of BM-MSCs in treating liver cirrhosis.

In a pilot study involving 40 patients with end-stage

Table 3: Therapeutic applications of bone marrow-derived MSCs in liver cirrhosis patients.

\begin{tabular}{|c|c|c|c|c|c|}
\hline Cell type & Dose & Route & Sample size (n) & Outcome & Reference \\
\hline BM-MSC & $\begin{array}{l}\text { Single median dose/ } \\
\text { unspecified }\end{array}$ & $\begin{array}{l}\text { Intrahepatic and } \\
\text { intrasplenic }\end{array}$ & 40 & $\begin{array}{l}\text { Increased serum albumin; } \\
\text { Decreased CPS, MELD score, } \\
\text { bilirubin and ascites }\end{array}$ & [40] \\
\hline BM-MSC & $\begin{array}{l}\text { Single median } \\
\text { dose } / 30-40 \times 10^{6}\end{array}$ & Peripheral vein & 4 & $\begin{array}{l}\text { Improved liver function and } \\
\text { Decreased MELD score }\end{array}$ & [48] \\
\hline BM-MSC & $\begin{array}{l}\text { Single median } \\
\text { dose } / 31.73 \times 10^{6}\end{array}$ & $\begin{array}{l}\text { Peripheral or the } \\
\text { portal vein }\end{array}$ & 8 & $\begin{array}{l}\text { Increased serum albumin; } \\
\text { Decreased MELD score, serum } \\
\text { creatinine, prothrombin, and } \\
\text { bilirubin }\end{array}$ & {$[10]$} \\
\hline BM-MSC & $\begin{array}{l}\text { Single median dose/ } \\
\text { unspecified }\end{array}$ & Hepaic artery & 572 & $\begin{array}{l}\text { Increased serum albumin; } \\
\text { Decreased MELD score and } \\
\text { serum bilirubin }\end{array}$ & {$[54]$} \\
\hline BM-MSC & $\begin{array}{l}\text { Single median dose } / 1 \\
\times 10^{6} \text { per } \mathrm{kg} \text { body } \\
\text { weight }\end{array}$ & Intravenous & 25 & $\begin{array}{l}\text { Improved serum albumin; } \\
\text { Decreased prothrombin, bilirubin } \\
\text { and MELD score }\end{array}$ & [55] \\
\hline BM-MSC & $\begin{array}{l}\text { Single median } \\
\text { dose } / 10 \times 10^{6}\end{array}$ & Intrasplenic & 20 & $\begin{array}{l}\text { Increased serum albumin; } \\
\text { Decreased serum bilirubin, AST, } \\
\text { ALT, prothrombin and INR }\end{array}$ & {$[56]$} \\
\hline BM-MSC & $\begin{array}{l}\text { Single median } \\
\text { dose } / 1.9 \times 10^{8}\end{array}$ & Peripheral vein & 27 & No significant improvement & [9] \\
\hline
\end{tabular}


liver failure, the transfusion of a single median dose of BM-MSCs through the intrasplenic $(n=10)$ and intrahepatic $(n=10)$ veins showed significant improvement in albumin and CPS levels as well as the MELD score. Ascites and bilirubin corresponding levels were also reduced [41]. There was a positive therapeutic effect of autologous BM-MSCs implantation in patients with end-stage liver disease associated with hepatitis or cryptogenic cirrhosis [10]. The liver function of patients in this study showed remarkable improvement after a cycle of peripheral or portal vein infusion of 30-50 million MSCs. The study suggests that the clinical outcome is not influenced by the routes of administration. In 2011, a larger clinical study evaluated the short- and long-term efficacy, and prognosis of autologous BM-MSCs in 572 liver failure patients [54]. This study measured the efficacy of BM-MSC transfusion through the hepatic artery 3 weeks and 192 weeks after transplantation. However, the number of BM-MSCs infused was not mentioned. The reduction of the MELD score and serum bilirubin levels coupled with the increase in serum albumin levels provides evidence that patient liver function improved significantly as compared to the control group.

A subsequent study in 2012 assessed the potential effects of hepatocyte-like cells differentiated from BMMSCs prior to infusion as compared to undifferentiated BM-MSCs in 25 liver cirrhosis patients [55]. While this study showed that the intravenous infusion of $1 \times$ $10^{6}$ cells per $\mathrm{kg}$ body weight is safe and improves liver function, the clinical outcomes between both treatment groups did not vary. The patients' prothrombin and serum albumin levels increased, while the bilirubin levels and MELD score decreased 3-9 months after infusion. Recently, a pilot study was conducted to evaluate the safety and efficacy of autologous BM-MSCs in 20 liver cirrhosis patients. These patients received an intrasplenic injection of $10 \times 10^{6} \mathrm{BM}-\mathrm{MSC}$ and were monitored for 10 months [56]. This study further validated that autologous BM-MSC transfusion significantly improves liver function, whereby the serum bilirubin, AST and ALT levels, prothrombin time and International Normalized Ratio (INR) decreased, while serum albumin levels increased. No serious adverse events were reported. The dosage of $1 \times 10^{6}$ cells per kg body weight also appears to be optimum.
In contrast, a randomized control study showed that ex vivo expanded BM-MSCs did not significantly improve the average liver function of $\mathbf{2 7}$ decompensated cirrhosis patients [9]. These patients were transfused with a median dose of $1.95 \times 10^{8}$ ex vivo expanded BM-MSCs via a peripheral vein and were followed up for 12 months. Based on the clinical outcomes, it was suggested that the autologous MSCs transplantation via peripheral vein may not be a viable therapeutic option for decompensated cirrhosis patients. It is suggested that either the hepatic artery or the portal vein may be a more ideal route of administration for BM-MSC transfusion in decompensated cirrhosis patients.

\section{Allogeneic Stem Cells in Liver Cirrhosis Therapy}

Although, autologous transplantation of stem cells has many advantages, under certain circumstances, it might not be a viable option. A major limitation is the ability to harvest sufficient numbers of potent stem cells, especially from elderly patients. Besides age-dependence, many patients who would benefit from stem-cell based therapy suffer from diseases that deplete their stem cell niches [57]. Hence for these patients, allogeneic stem cells become the most viable option. The clinical utility of allogeneic MSCs has been explored in many cell-based therapies. These cells have the ability to evade graft-versus-host rejection due to their unique immunosuppressive and immunosurveillance capacities. HSCs do not have the same immunomodulatory ability [58]. These MSCs can be isolated from umbilical cord or cord blood, placenta and amniotic fluid. They have been shown to be more potent than BM-MSCs [59-62]. With respect to the involvement of MSCs in liver regenerative medicine, many studies have demonstrated that the infusion of human umbilical cord- or cord blood-derived MSCs via a vein or multiple direct injections into the liver effectively relieves liver cirrhosis and improves the survival rate in rodent models. These studies also suggest that multiple infusions show better clinical outcomes as compared to a single infusion of allogeneic MSCs [62-65].

Based on this pre-clinical evidence, a considerable number of clinical studies have provided sufficient evidence to suggest that the administration of allogeneic MSCs is safe and ameliorates liver function in patients with end-stage liver diseases (Table 4). An open labeled

Table 4: Alternative therapeutic applications of allogeneic MSCs in liver cirrhosis patients

\begin{tabular}{|c|c|c|c|c|c|}
\hline Cell type & Dose & Route & Sample size (n) & Outcome & Reference \\
\hline UC-MSC & $\begin{array}{l}\text { Three median doses } / 0.5 \times \\
10^{6} \text { per kg body weight }\end{array}$ & Intravenous & 43 & $\begin{array}{l}\text { Increased serum albumin, } \\
\text { cholinesterase and platelet; } \\
\text { Decreased MELD score, prothrombin } \\
\text { time, total bilirubin and ALT }\end{array}$ & {$[66]$} \\
\hline UC-MSC & $\begin{array}{l}\text { Three median doses } / 0.5 \times \\
10^{6} \text { per kg body weight }\end{array}$ & Intravenous & 7 & $\begin{array}{l}\text { Decreased serum } \\
\text { alkaline phosphatase and } \\
\text { Y-glutamyltransferase }\end{array}$ & [25] \\
\hline UC-MSC & $\begin{array}{l}\text { Three median doses } / 0.5 \times \\
10^{6} \text { per kg body weight }\end{array}$ & Intravenous & 45 & Improvement in liver function & [25] \\
\hline UB-MSC & Single median dose/1.5 $\times 10^{7}$ & Percutaneous & 51 & Improved QULI & [73] \\
\hline
\end{tabular}


parallel-controlled phase I/II trial involving 43 patients with acute-on-chronic liver failure demonstrated that the infusion of human Umbilical Cord-Derived Mesenchymal Stem Cells (UC-MSCs) through intravenous injection was safe and well tolerable [66]. In this study 24 patients were subjected to intravenous administration of UC-MSCs ( $0.5 \times 10^{6}$ per kg body weight) at 4-week intervals remaining and 19 patients were treated with saline as controls. The patients experienced improvements in their liver function, whereby their serum albumin, prothrombin activity, cholinesterase and platelet counts increased, while their MELD score, and total bilirubin and ALT decreased.

Another study probed into the safety and efficacy of UC-MSCs in patients with decompensated liver cirrhosis [25]. A total of 45 patients were recruited in this study and the study group patients $(n=30)$ were transfused intravenously with 0.5 million UC-MSCs per $\mathrm{kg}$ body weight thrice at 4-week intervals. After one year of follow-up, significant improvement in liver functions were noted in the UC-MSC treatment group. The safety and feasibility of UC-MSC transfusions have also been evaluated in liver cirrhosis patients with primary biliary cirrhosis. The single-arm study patients $(n=7)$ received $0.5 \times 10^{6}$ UC-MSCs per kg body weight intravenously thrice at 4-week intervals. At the end of 48 weeks post-transplantation, the liver function was increased in all patients. This observation was based on the significant improvement in serum alkaline phosphatase and gamma-glutamyltransferase levels as compared to the baseline report [26].

Similarly, the Umbilical cord Blood derived-Mesenchymal Stem Cells (UB-MSCs) are also well tolerable in patients with liver cirrhosis [67]. In this study, a total of 51 patients were enrolled and transfused with 1.5 $\times 10^{7}$ UB-MSCs percutaneously directly into parenchyma. In this study, UB-MSC therapy prolonged patients' lives and improved their quality of life. Although only few clinical trials have been conducted, and there are overt limitations to each of these trials, it is proposed that multiple infusions (either systemic or selected artery delivery) of allogeneic MSCs $\left(0.5 \times 10^{6}\right)$ is a viable approach in the management of liver cirrhosis.

\section{Future Perspectives}

Although multiple clinical trials and pilot studies have indicated to the exciting potential of the clinical utility of autologous or allogeneic stem cells in the management of liver cirrhosis, the exact reproducible therapeutic recommendation remains inconclusive. This is due to the different technical approaches across all the different studies. While it is difficult to control for the different natural histories of liver cirrhosis patients, future studies should focus on selection of homogenous groups of clinical patients. This will facilitate standardization of clinical protocols to achieve comparable and measurable endpoints. To achieve this, patient selection can be improved by using defined "inclusion and exclusion criteria" for different types or degree of severity of cirrhosis. The factors that can be used to determine the "inclusion and exclusion criteria" for different degrees of severity of cirrhosis include total bilirubin, albumin and globulin levels, Prothrombin time, CPS and MELD scores. There are 2 types of liver cirrhosis, which are broadly classified into alcoholic and non-alcoholic liver cirrhosis. Based on this classification, therapeutic strategy can be optimized for different types of cirrhosis, such as dose, mode of administration and frequency of transplantation (Figure 2). For example, the administration of stem cells through the

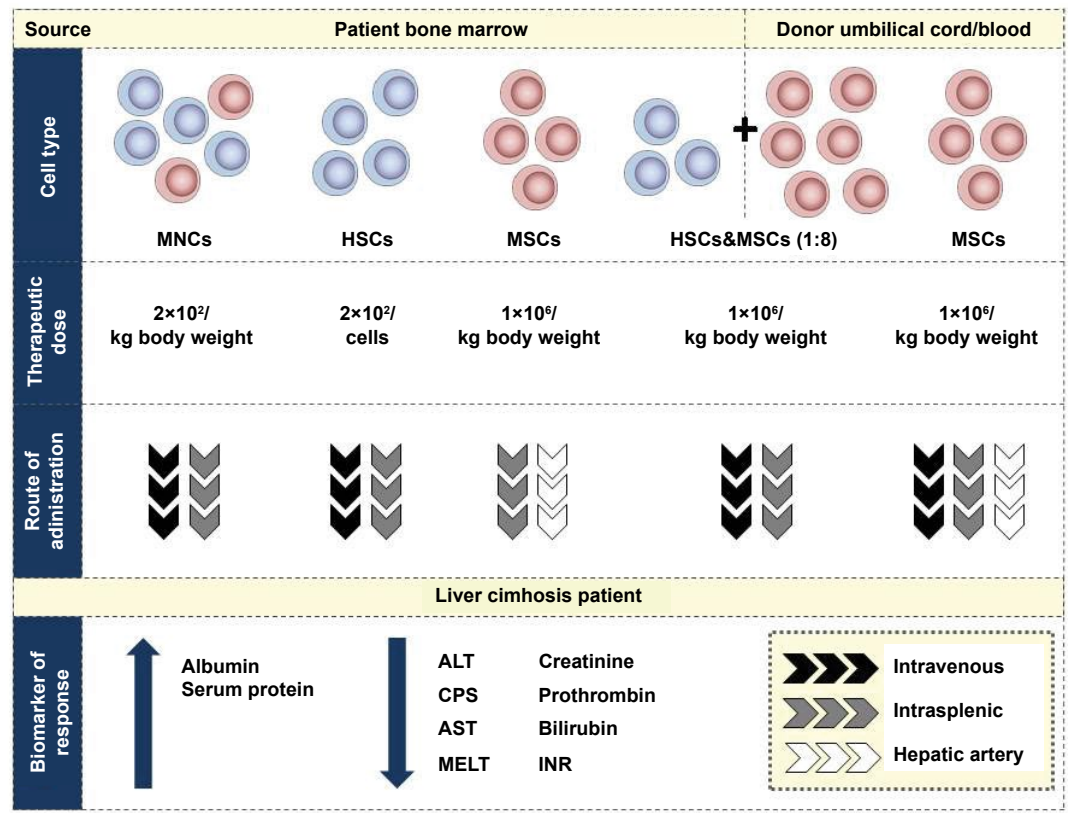

Figure 2: Summary of most effective dose and route of administration of adult stem cells based on the source and type of cells for liver cirrhosis therapy. The improvement in liver function is determined based on the levels and activity of several biomarkers. The data is collated from the various studies that have been conducted in liver cirrhosis to date. 
hepatic artery showed more promising results in patients with alcoholic liver cirrhosis as compared to systemic administration. Disease-specific optimization of stem cell therapy will improve the patient life.

Based on the various studies reviewed here, $2 \times 10^{8}$ per kg body weight of BM-MNCs, $2 \times 10^{8}$ of BM-HSCs and 1 million per kg body weight of autologous or allogeneic MSCs would be a good starting infusion cell number in future studies or applications. With regards to the route of administration, the systemic transplantation (intravenous) of stem cells is the easiest approach. However since this route requires homing to the target site, the therapeutic efficiency is potentially minimized. Although HSCs and MSCs have considerable homing ability, direct infusion (hepatic artery or intrasplenic) of stem cells would enhance the liver regeneration effect. In addition, to mitigate disease progression and maintain the physiological state, multiple infusions of stem cells may improve the quality of life along with increased liver function.

It has been established that each type and source of adult stem cells has their own liver regeneration potency. In comparison to the infusion of specific stem cells, the infusion of mixed population of stem cells derived from the bone marrow may have synergistic effect in liver regeneration. For example, MSCs have been recognized as an imperative constituent of HSC niche, whereby they enhance the ability of HSCs to grow, sustain, home and differentiate by secreting various cytokines, growth factors and matrix proteins. Thus, MSCs are considered as an essential supportive scaffold for HSC in vivo. In non-obese diabetic/severe combined immunodeficiency mice, it was shown that MSCs promote the engraftment of UB-HSCs by modulating alloreactivity [67]. Another pilot study reported that the co-transplantation BM-MSC and peripheral blood stem cells was well-tolerated and improved disease prognosis [68]. Several clinical studies have demonstrated that the collective stem cell populations from the bone marrow have produced promising clinical outcomes in bone vascularization [69] and heart failure therapy [70]. However, the symbiotic relationship between HSCs and MSCs in liver regeneration has not yet been determined. No studies have been conducted to directly compare the efficacy of infusion of specific stem cells and mixed population cells in the context of liver regeneration. If a synergetic effect is proven, the optimal ratio of the mixed stem cell population needs to be determined in order to maximize clinical potential.

The bone marrow is a major reservoir for HSCs and MSCs but insufficient numbers of stem cell populations in individual patients limit the viability of cell-based therapies via intravenous, intrasplenic or the hepatic artery. To overcome this problem, ex vivo expansion of HSCs and MSCs has been studied extensively. Nevertheless, the effective optimal ratio of HSCs and MSCs has not yet been determined. One pre-clinical study reported that 1:8 to $1: 16$ ratio of HSCs and MSCs co-transplantation might enhance engraftment efficacy. This study also suggested that by increasing the proportion of MSCs, the engraftment efficacy was repressed [71]. Although the therapeutic efficacy of HSC and MSC co-transplantation was more significant than the individual components alone, more clinical data pertaining to safety and viability is required before effective translation into the clinic can be instituted. Nonetheless, in the near future, it is expected that once the various knowledge gaps are bridged, co-transplantation of autologous or allogeneic ex vivo expanded combination of stem cells will transform the management of liver cirrhosis.

\section{Conflict of Interest}

The authors express no conflicts of interest towards the publication of this paper.

\section{References}

1. Pinzani M, Rosselli M, Zuckermann M (2011) Liver cirrhosis. Best Pract Res Clin Gastroenterol 25: 281-290.

2. Zhou WC, Zhang QB, Qiao L (2014) Pathogenesis of liver cirrhosis. World J Gastroenterol 20: 7312-7324.

3. Mokdad AA, Lopez AD, Shahraz S, Lozano R, Mokdad AH, et al. (2014) Liver cirrhosis mortality in 187 countries between 1980 and 2010: A systematic analysis. BMC Med 12: 145.

4. Dienstag JL, Cosimi AB (2012) Liver transplantation-a vision realized. N Engl J Med 367: 1483-1485.

5. Roberts MS, Angus DC, Bryce CL, Valenta Z, Weissfeld $L$ (2004) Survival after liver transplantation in the United States: A disease-specific analysis of the UNOS database. Liver Transpl 10: 886-897.

6. Puglisi MA, Tesori V, Lattanzi W, Piscaglia AC, Gasbarrini GB, et al. (2011) Therapeutic implications of mesenchymal stem cells in liver injury. J Biomed Biotechnol 2011: 860578.

7. Haque S, Haruna Y, Saito K, Nalesnik MA, Atillasoy E, et al. (1996) Identification of bipotential progenitor cells in human liver regeneration. Lab Invest 75: 699-705.

8. Theise ND, Saxena R, Portmann BC, Thung SN, Yee H, et al. (1999) The canals of Hering and hepatic stem cells in humans. Hepatology 30: 1425-1433.

9. Mohamadnejad M, Alimoghaddam K, Bagheri M, Ashrafi M, Abdollahzadeh L, et al. (2013) Randomized placebo-controlled trial of mesenchymal stem cell transplantation in decompensated cirrhosis. Liver Int 33: 1490-1496.

10. Kharaziha P, Hellström PM, Noorinayer B, Farzaneh F, Aghajani K, et al. (2009) Improvement of liver function in liver cirrhosis patients after autologous mesenchymal stem cell injection: A phase I-II clinical trial. Eur J Gastroenterol Hepatol 21: 1199-1205.

11. Kim JK, Park YN, Kim JS, Park MS, Paik YH, et al. (2010) Autologous bone marrow infusion activates the progenitor cell compartment in patients with advanced liver cirrhosis. Cell Transplant 19: 1237-1246.

12. Jang YY, Collector MI, Baylin SB, Diehl AM, Sharkis SJ (2004) Hematopoietic stem cells convert into liver cells within days without fusion. Nat Cell Biol 6: 532-539. 
13. Sato $\mathrm{Y}$, Araki $\mathrm{H}$, Kato J, Nakamura $\mathrm{K}$, Kawano $\mathrm{Y}$, et al. (2005) Human mesenchymal stem cells xenografted directly to rat liver are differentiated into human hepatocytes without fusion. Blood 106: 756-763.

14. Liu F, Pan X, Chen G, Jiang D, Cong X, et al. (2006) Hematopoietic stem cells mobilized by granulocyte colony-stimulating factor partly contribute to liver graft regeneration after partial orthotopic liver transplantation. Liver Transpl 12: 1129-1137.

15. Zhang Z, Wang FS (2013) Stem cell therapies for liver failure and cirrhosis. J Hepatol 59: 183-185.

16. Prosser CC, Yen RD, Wu J (2006) Molecular therapy for hepatic injury and fibrosis: Where are we? World J Gastroenterol 12: 509-515.

17. Kim WH, Matsumoto K, Bessho K, Nakamura T (2005) Growth inhibition and apoptosis in liver myofibroblasts promoted by hepatocyte growth factor leads to resolution from liver cirrhosis. Am J Pathol 166: 1017-1028.

18. Huang $P, H e Z$, Ji S, Sun H, Xiang D, et al. (2011) Induction of functional hepatocyte-like cells from mouse fibroblasts by defined factors. Nature 475: 386-389.

19. Teramoto K, Hara Y, Kumashiro Y, Chinzei R, Tanaka Y, et al. (2005) Teratoma formation and hepatocyte differentiation in mouse liver transplanted with mouse embryonic stem cell-derived embryoid bodies. Transplant Proc 37: 285-286.

20. Terai S, Ishikawa T, Omori K, Aoyama K, Marumoto Y, et al. (2006) Improved liver function in patients with liver cirrhosis after autologous bone marrow cell infusion therapy. Stem Cells 24: 2292-2298.

21. Khan AA, Parveen N, Mahaboob VS, Rajendraprasad A, Ravindraprakash HR, et al. (2008) Safety and efficacy of autologous bone marrow stem cell transplantation through hepatic artery for the treatment of chronic liver failure: $A$ preliminary study. Transplant Proc 40: 1140-1144.

22. Lyra AC, Soares MB, da Silva LF, Fortes MF, Silva AG, et al. (2007) Feasibility and safety of autologous bone marrow mononuclear cell transplantation in patients with advanced chronic liver disease. World J Gastroenterol 13: 1067-1073.

23. Lee KD, Kuo TK, Whang-Peng J, Chung YF, Lin CT, et al. (2004) In vitro hepatic differentiation of human mesenchymal stem cells. Hepatology 40: 1275-1284.

24. Salama H, Zekri AR, Bahnassy AA, Medhat E, Halim HA, et al. (2010) Autologous CD34+ and CD133+ stem cells transplantation in patients with end stage liver disease. World $J$ Gastroenterol 16: 5297-5305.

25. Zhang Z, Lin H, Shi M, Xu R, Fu J, et al. (2012) Human umbilical cord mesenchymal stem cells improve liver function and ascites in decompensated liver cirrhosis patients. $J$ Gastroenterol Hepatol 27: 112-120.

26. Wang L, Li J, Liu H, Li Y, Fu J, et al. (2013) Pilot study of umbilical cord-derived mesenchymal stem cell transfusion in patients with primary biliary cirrhosis. J Gastroenterol Hepatol 28: 85-92.

27. Preston SL, Alison MR, Forbes SJ, Direkze NC, Poulsom $R$, et al. (2003) The new stem cell biology: something for everyone. Mol Pathol 56: 86-96.

28. Prasajak P, Leeanansaksir W (2014) Mesenchymal stem cells: Current clinical applications and therapeutic potential in liver diseases. J Bone Marrow Res 2: 137.

29. Bian ZY, Li G, Gan YK, Hao YQ, Xu WT, et al. (2009) Increased number of mesenchymal stem cell-like cells in peripheral blood of patients with bone sarcomas. Arch Med Res 40: 163-168.
30. Pilat N, Unger L, Berlakovich GA (2013) Implication for bone marrow derived stem cells in hepatocyte regeneration after orthotopic liver transplantation. Int J Hepatol 2013: 310612.

31. Huebert RC, Rakela J (2014) Cellular therapy for liver disease. Mayo Clin Proc 89: 414-424.

32. Vainshtein JM, Kabarriti R, Mehta KJ, Roy-Chowdhury J, Guha C (2014) Bone marrow-derived stromal cell therapy in cirrhosis: Clinical evidence, cellular mechanisms, and implications for the treatment of hepatocellular carcinoma. Int J Radiat Oncol Biol Phys 89: 786-803.

33. Okazaki I, Watanabe T, Hozawa S, Arai M, Maruyama K (2000) Molecular mechanism of the reversibility of hepatic fibrosis: With special reference to the role of matrix metalloproteinases. J Gastroenterol Hepatol 15: 26-32.

34. Rajkumar J, Baskar S, Senthil Nagarajan R, Murugan $P$, Terai S, et al. (2007) Autologous Bone Marrow stem cell Infusion (AMBI) therapy for chronic liver diseases. J Stem Cells Regen Med 3: 26-37.

35. Saito T, Okumoto K, Haga H, Nishise Y, Ishii R, et al. (2011) Potential therapeutic application of intravenous autologous bone marrow infusion in patients with alcoholic liver cirrhosis. Stem Cells Dev 20: 1503-1510.

36. Spahr L, Chalandon Y, Terraz S, Kindler V, Rubbia-Brandt $\mathrm{L}$, et al. (2013) Autologous bone marrow mononuclear cell transplantation in patients with decompensated alcoholic liver disease: A randomized controlled trial. PLoS One 8: e53719.

37. Fox IJ, Chowdhury JR, Kaufman SS, Goertzen TC, Chowdhury NR, et al. (1998) Treatment of the Crigler-Najjar syndrome type I with hepatocyte transplantation. N Engl J Med 338: $1422-1426$.

38. Muraca M, Gerunda G, Neri D, Vilei MT, Granato A, et al. (2002) Hepatocyte transplantation as a treatment for glycogen storage disease type 1a. Lancet 359: 317-318.

39. Li Z, He C, Xiao J, Chen ZY (2013) Treating end-stage liver diseases with mesenchymal stem cells: An oak is not felled at one stroke. OA Tissue Engineering 1: 3.

40. Liu WH, Song FQ, Ren LN, Guo WQ, Wang T, et al. (2015) The multiple functional roles of mesenchymal stem cells in participating in treating liver diseases. J Cell Mol Med 19: 511-520.

41. Amer ME, El-Sayed SZ, El-Kheir WA, Gabr H, Gomaa AA, et al. (2011) Clinical and laboratory evaluation of patients with end-stage liver cell failure injected with bone marrow-derived hepatocyte-like cells. Eur J Gastroenterol Hepatol 23: 936-941.

42. Sellamuthu S, Manikandan R, Thiagarajan R, Babu G, Dinesh D, et al. (2011) In vitro trans-differentiation of human umbilical cord derived hematopoietic stem cells into hepatocyte like cells using combination of growth factors for cell based therapy. Cytotechnology 63: 259-268.

43. Alison MR, Poulsom R, Jeffery R, Dhillon AP, Quaglia A, et al. (2000) Hepatocytes from non-hepatic adult stem cells. Nature 406: 257.

44. Piscaglia AC, Shupe TD, Oh SH, Gasbarrini A, Petersen BE (2007) Granulocyte-colony stimulating factor promotes liver repair and induces oval cell migration and proliferation in rats. Gastroenterology 133: 619-631.

45. Yannaki E, Anagnostopoulos A, Kapetanos D, Xagorari A, lordanidis F, et al. (2006) Lasting amelioration in the clinical course of decompensated alcoholic cirrhosis with boost infusions of mobilized peripheral blood stem cells. Exp Hematol 34: 1583-1587. 
46. Natori T, Sata M, Washida M, Hirata $Y$, Nagai $R$, et al. (2002) G-CSF stimulates angiogenesis and promotes tumor growth: Potential contribution of bone marrow-derived endothelial progenitor cells. Biochem Biophys Res Commun 297: 1058-1061.

47. Veerappan R, Morrison M, Williams S, Variakojis D (2007) Splenic rupture in a patient with plasma cell myeloma following G-CSF/GM-CSF administration for stem cell transplantation and review of the literature. Bone Marrow Transplant 40: 361-364.

48. Mohamadnejad M, Alimoghaddam K, Mohyeddin-Bonab M, Bagheri M, Bashtar M, et al. (2007) Phase 1 trial of autologous bone marrow mesenchymal stem cell transplantation in patients with decompensated liver cirrhosis. Arch Iran Med 10: 459-466.

49. Stutchfield BM, Forbes SJ, Wigmore SJ (2010) Prospects for stem cell transplantation in the treatment of hepatic disease. Liver Transpl 16: 827-836.

50. Gordon MY, Levicar N, Pai M, Bachellier P, Dimarakis I, et al. (2006) Characterization and clinical application of human CD34+ stem/progenitor cell populations mobilized into the blood by granulocyte colony-stimulating factor. Stem Cells 24: 1822-1830.

51. Pai M, Zacharoulis D, Milicevic MN, Helmy S, Jiao LR, et al. (2008) Autologous infusion of expanded mobilized adult bone marrow-derived CD34+ cells into patients with alcoholic liver cirrhosis. Am J Gastroenterol 103: 1952-1958.

52. Levicar N, Pai M, Habib NA, Tait P, Jiao LR, et al. (2008) Long-term clinical results of autologous infusion of mobilized adult bone marrow derived CD34+ cells in patients with chronic liver disease. Cell Prolif 41: 115-125.

53. Newman RE, Yoo D, LeRoux MA, Danilkovitch-Miagkova A (2009) Treatment of inflammatory diseases with mesenchymal stem cells. Inflamm Allergy Drug Targets 8: 110-123.

54. Peng L, Xie DY, Lin BL, Liu J, Zhu HP, et al. (2011) Autologous bone marrow mesenchymal stem cell transplantation in liver failure patients caused by hepatitis B: Short-term and long-term outcomes. Hepatology 54: 820-828.

55. El-Ansary M, Abdel-Aziz I, Mogawer S, Abdel-Hamid S, Hammam O, et al. (2012) Phase II trial: Undifferentiated versus differentiated autologous mesenchymal stem cells transplantation in Egyptian patients with HCV induced liver cirrhosis. Stem Cell Rev 8: 972-981.

56. Amin MA, Sabry D, Rashed LA, Aref WM, el-Ghobary MA, et al. (2013) Short-term evaluation of autologous transplantation of bone marrow-derived mesenchymal stem cells in patients with cirrhosis: Egyptian study. Clin Transplant 27: 607-612.

57. Das AK, Bin Abdullah BJ, Dhillon SS, Vijanari A, Anoop CH et al. (2013) Intra-arterial allogeneic mesenchymal stem cells for critical limb ischemia are safe and efficacious: Report of a phase I study. World J Surg 37: 915-922.

58. Ryan JM, Barry FP, Murphy JM, Mahon BP (2005) Mesenchymal stem cells avoid allogeneic rejection. J Inflamm (Lond) 2: 8.

59. Hass R, Kasper C, Böhm S, Jacobs R (2011) Different populations and sources of human mesenchymal stem cells
(MSC): A comparison of adult and neonatal tissue-derived MSC. Cell Commun Signal 9: 12.

60. Lee OK, Kuo TK, Chen WM, Lee KD, Hsieh SL, et al. (2004) Isolation of multipotent mesenchymal stem cells from umbilical cord blood. Blood 103: 1669-1675.

61. Tong CK, Vellasamy S, Tan BC, Abdullah M, Vidyadaran S, et al. (2011) Generation of mesenchymal stem cell from human umbilical cord tissue using a combination enzymatic and mechanical disassociation method. Cell Biol Int 35: 221-226.

62. Troyer DL, Weiss ML (2008) Wharton's jelly-derived cells are a primitive stromal cell population. Stem Cells 26: 591-599.

63. Hong J, Jin H, Han J, Hu H, Liu J, et al. (2014) Infusion of human umbilical cord derived mesenchymal stem cells effectively relieves liver cirrhosis in DEN induced rats. Mol Med Rep 9: 1103-1111.

64. Jung KH, Shin HP, Lee S, Lim YJ, Hwang SH, et al. (2009) Effect of human umbilical cord blood-derived mesenchymal stem cells in a cirrhotic rat model. Liver Int 29: 898-909.

65. Shi LL, Liu FP, Wang DW (2011) Transplantation of human umbilical cord blood mesenchymal stem cells improves survival rates in a rat model of acute hepatic necrosis. Am J Med Sci 342: 212-217.

66. Shi M, Zhang Z, Xu R, Lin H, Fu J, et al. (2012) Human mesenchymal stem cell transfusion is safe and improves liver function in acute-on-chronic liver failure patients. Stem Cells Transl Med 1: 725-731.

67. Noort WA, Kruisselbrink AB, Anker PS, Kruger M, van Bezooijen RL, et al. (2002) Mesenchymal stem cells promote engraftment of human umbilical cord blood-derived CD34(+) cells in NOD/SCID mice. Exp Hematol 30: 870-878.

68. Wu T, Bai H, Wang CB, Zhang Q, Tantai LF, et al. (2009) Autologous bone marrow-derived mesenchymal stem cells and peripheral blood stem cells cotransplantation in treatment of hematological malignant diseases. Zhonghua Nei Ke Za Zhi 48: 392-395.

69. Moioli EK, Clark PA, Chen M, Dennis JE, Erickson HP, et al. (2008) Synergistic actions of hematopoietic and mesenchymal stem/progenitor cells in vascularizing bioengineered tissues. PLoS One 3: e3922.

70. Ichim TE, Solano F, Lara F, Rodriguez JP, Cristea O, et al. (2010) Combination stem cell therapy for heart failure. Int Arch Med 3: 5 .

71. Kim DH, Yoo KH, Yim YS, Choi J, Lee SH, et al. (2006) Cotransplanted bone marrow derived mesenchymal stem cells (MSC) enhanced engraftment of hematopoietic stem cells in a MSC-dose dependent manner in NOD/SCID mice. J Korean Med Sci 21: 1000-1004.

72. Lyra AC, Soares MB, da Silva LF, Braga EL, Oliveira SA, et al. (2010) Infusion of autologous bone marrow mononuclear cells through hepatic artery results in a short-term improvement of liver function in patients with chronic liver disease: $A$ pilot randomized controlled study. Eur J Gastroenterol Hepatol 22: 33-42.

73. Jong YB, Zhengfu $P$, Jae HJ, Hoon H (2011) Treatment of the end Stage Liver Cirrhosis by Human Umbilical Cord Blood Stem Cells: Preliminary Results. In: A Gholamrezanezhad, Stem Cells in Clinic and Research. InTech 469-500. 